\title{
AN OPPOSING ROLE FOR THE ADRENALS IN THE HYPOTENSIVE EFFECTS OF PROPRANOLOL IN THE SPONTANEOUSLY HYPERTENSIVE RAT
}

\author{
FRANS P. NIJKAMP, RENÉE VAN DEN BOSCH and WYBREN DE JONG \\ Rudolf Magnus Institute for Pharmacology, University of Utrecht, Medical Faculty, Vondellaan 6, Utrecht, \\ The Netherlands
}

Received 8 December 1978, accepted 27 March 1979

F.P. NIJKAMP, R. VAN DEN BOSCH and W. DE JONG, An opposing role for the adrenals in the hypotensive effects of propranolol in the spontaneously hypertensive rat, European J. Pharmacol. 56 (1979) $187-195$.

d,l-Propranolol ( 1 and $5 \mathrm{mg} / \mathrm{kg} \mathrm{s.c.)} \mathrm{did} \mathrm{not} \mathrm{cause} \mathrm{a} \mathrm{fall} \mathrm{in} \mathrm{blood} \mathrm{pressure} \mathrm{and} \mathrm{induced} \mathrm{only} \mathrm{a} \mathrm{limited} \mathrm{decrease}$ in heart rate in conscious spontaneously hypertensive rats (SHR). In contrast, after bilateral adrenalectomy, d,lpropranolol induced a rapid and profound decrease in blood pressure and heart rate. Decreases in heart rate and blood pressure in the individual animals were not correlated. The effects were mainly caused by l-propranolol but an additional effect of d-propranolol cannot be excluded. The decrease in blood pressure was not observed after removal of the adrenal medulla. Heart rate decreased only slightly in these animals. After treatment of adrenalectomized SHR with corticosterone $(1 \mathrm{mg} / \mathrm{kg} \mathrm{b.w./h})$ the decrease in blood pressure due to d,l-propranolol was completely abolished. The fall in heart rate was diminished. Central injection of d,l-propranolol into the lateral brain ventricle of adrenalectomized SHR caused cardiovascular changes which were less pronounced than those following peripheral injection of comparable doses. The inhibitory effects of d,l-propranolol also occurred in adrenalectomized normotensive Wistar Kyoto rats. However, no significant changes in blood pressure and only a limited fall in heart rate were observed in adrenalectomized normotensive and renal hypertensive Wistar rats. It is concluded that the presence of the adrenal cortex, but not of the adrenal medulla prevents acute hypotension and bradycardia after propranolol in the conscious SHR.

Spontaneously hypertensive rat Hypotension and bradycardia Propranolol Adrenalectomy Corticosteroids

\section{Introduction}

The anti-hypertensive effect of propranolol in various types of hypertension in man has been well documented (Prichard and Gillam, 1969; Frolich et al., 1968; Bühler et al., 1972; Zacharias et al., 1972). In the rat with experimental hypertension however, the blood pressure lowering effect is less clear (Farmer and Levy, 1968; Menard et al., 1973; Lundgren, 1974; Fernandes et al., 1976; Leenen and Ackerman, 1976). There is some evidence that the spontaneously hypertensive rat (SHR, Wistar Kyoto strain) may be a relatively sensitive laboratory animal for observing the anti-hypertensive effects of $\beta$-adrenergic block- ing drugs (Roba et al., 1972; Vavra et al., 1973; Weiss et al., 1974; Forman and Mulrow, 1974).

The decrease in blood pressure after systemic administration of propranolol in the SHR generally occurs after 2-3 days of treatment (Forman and Mulrow, 1974; Sweet et al., 1977). The mechanism of action has not yet been fully elucidated. Both a peripherally mediated mechanism and a centrally mediated one merit consideration (Tarazi and Dustan, 1972; Bühler et al., 1973; Day and Roach, 1974; Reid et al., 1974; Garvey and Ram, 1975; Ram et al., 1977). Neither of the proposed mechanisms of action however gives a satisfactory explanation for the dif- 
ferences in hypotensive activity of propranolol in several types of hypertension. Recently however, Buckenham et al. (1978) reported that adrenal catecholamines in DOCA-saline hypertensive rats moderated the hypotensive effect of high doses of the non-selective $\beta$-adrenoceptor blocking drug pindolol.

In the present study we investigated the role of the adrenals in the acute cardiovascular effects of propranolol in SHR.

\section{Materials and methods}

Male spontaneously hypertensive rats of the Wistar Kyoto strain (SHR/NIH-Cpb) aged 11-15 weeks were used. The blood pressure was recorded in conscious animals from a cannula (PE25 connected to a PE60 cannula) in the caudal artery at the base of the tail, by a Statham transducer (model P23Ac) connected to a Grass polygraph. The heart rate was calculated from the blood pressure tracings. Cannulas were implanted under ether anesthesia $4-5 \mathrm{~h}$ before the experiment was started.

Renal hypertension was induced by applying a solid silver clip (internal diameter $0.20 \mathrm{~mm}$ ) on the left renal artery of male Wistar rats weighing 130-160 g (Leenen and De Jong, 1971). This procedure results in a regular development of hypertension, reaching a plateau 3-4 weeks after the operation. The hypertensive rats were used $3-4$ weeks after application of the clip. The body weight range at that time was $180-250 \mathrm{~g}$.

Effects of propranolol in normotensive Wistar Kyoto and Wistar rats were assessed in groups age-matched with the hypertensive animals.

Injections into the central nervous system were given into the lateral ventricle via a permanently implanted cannula as described by Hayden et al. (1966).

Bilateral adrenalectomy or nephrectomy was carried out under ether anesthesia $4-5 \mathrm{~h}$ before the experiment was started. Removal of the adrenal medulla was done under ether anesthesia 2 days before the experiment by making a small incision in the adrenal and softly pushing out the medulla.

d,l-Propranolol (propranolol hydrochloride, ICI), d-propranolol (ICI), l-propranolol (ICI) or vehicle $(0.9 \% \mathrm{NaCl})$ were injected subcutaneously in a volume of $1 \mathrm{ml} / \mathrm{kg}$ body weight or dissolved in a volume of $2 \mu \mathrm{l}$ saline for CNS injection. Substitution therapy was carried out with corticosterone $(25 \mathrm{mg} / \mathrm{ml}$ in ethanol diluted with saline).

Results are expressed as means \pm standard of the mean (SEM). The significance of the difference between values for the control and treated groups was determined with Student's $t$-test. $\mathrm{P}$ values less than 0.05 were considered significant.

\section{Results}

Two different doses of d,l-propranolol (1 and $5 \mathrm{mg} / \mathrm{kg}$ s.c.) failed to decrease blood pressure during the $2 \mathrm{~h}$ of measurement in intact SHR (table 1). A small increase was observed $5 \mathrm{~min}$ after the administration and for the lowest dose this was followed by a small decrease after $120 \mathrm{~min}$. With the highest dose, the heart rate decreased significantly by a maximum of $50 \pm 6 \mathrm{bpm}$.

Administration of $\mathrm{d}$,l-propranolol to animals bilaterally adrenalectomized $4-5 \mathrm{~h}$ previously however induced a profound decrease in blood pressure and heart rate (fig. 1). Maximal effects were observed $30 \mathrm{~min}$ after the injection $(-34 \pm 6 \mathrm{~mm} \mathrm{Hg}$ and $-140 \pm 8 \mathrm{bpm}$ respectively after $5 \mathrm{mg} / \mathrm{kg}$ ). After $120 \mathrm{~min}$ both parameters in both groups of rats were still significantly different from their respective control values. The individual values for decrease in blood pressure and heart rate $30 \mathrm{~min}$ after propranolol $(5 \mathrm{mg} / \mathrm{kg})$ were not correlated $(\mathrm{r}=0.25)$.

In the adrenalectomized rats receiving $d, 1-$ propranolol there was a marked fluctuation of the blood pressure when it was maximally decreased (fig. 2). No simultaneous changes in heart rate occurred however. 
TABLE 1

Effect of various doses of d,l-propranolol (s.c.) on mean blood pressure and heart rate of conscious spontaneously hypertensive rats.

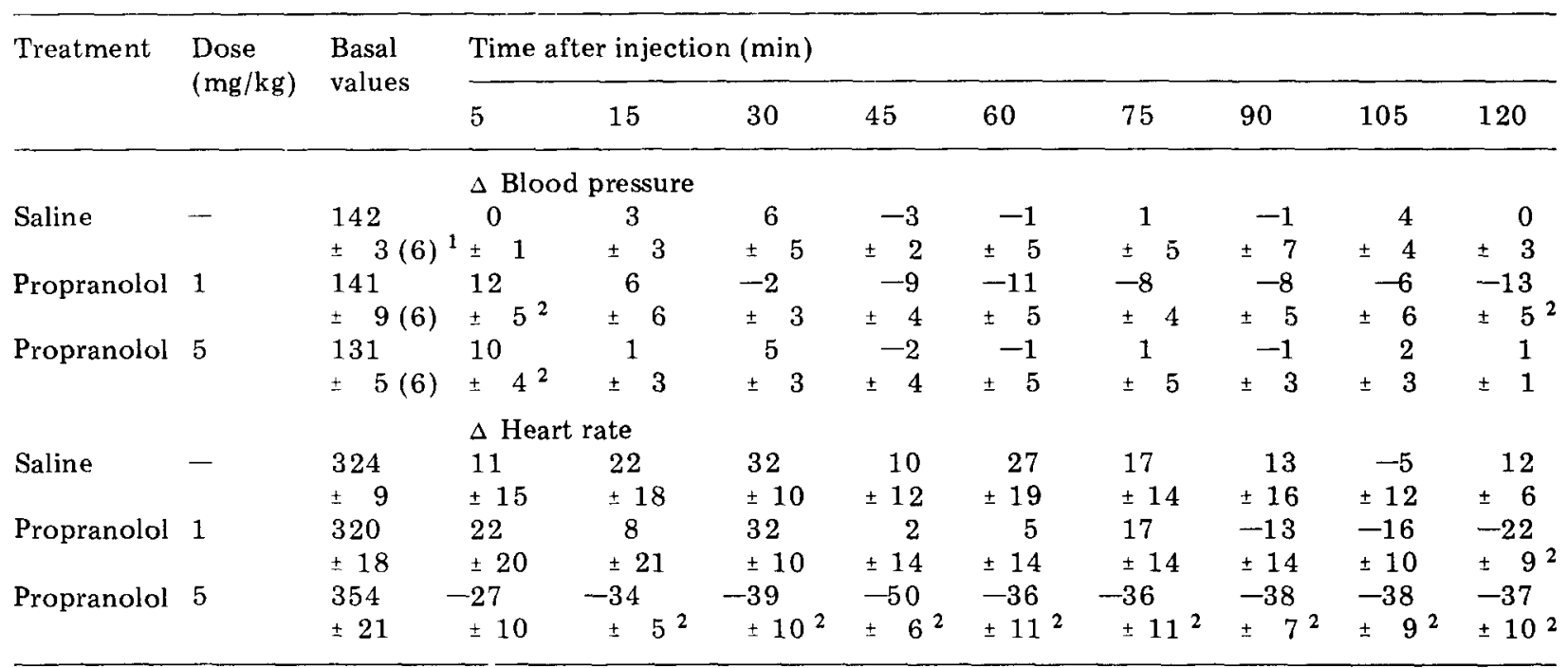

1 Number of animals is given in parentheses.

$2 \mathrm{P}<0.05$, compared to corresponding control value (saline treatment).

In order to investigate the effect of the isomers on blood pressure and heart rate $\mathrm{d}$ and 1-propranolol $(2.5$ and $5 \mathrm{mg} / \mathrm{kg})$ were administered to different groups of adrenalectomized SHR. The maximal responses 1530 min after administration of $\mathrm{l}$ - and $\mathrm{d}$ propranolol are depicted in fig. 3. A dosedependent fall in heart rate was observed after l-propranolol. The hypotension and bradycardia after d-propranolol were much less pronounced. After the highest dose responses were less than half those observed after $5 \mathrm{mg} /$ kg l-propranolol.

To investigate whether the adrenal cortex or the adrenal medulla was responsible for the influence of the adrenals, $d, l$-propranolol was administered to demedullated animals. In these rats $\mathrm{d}$,l-propranolol $(5 \mathrm{mg} / \mathrm{kg})$ caused no significant decrease of blood pressure. The heart rate showed only a limited decrease from 15-60 min after the d,l-propranolol injection (fig. 4). After treatment of adrenalectomized animals with corticosterone (1 mg/ $\mathrm{kg} \mathrm{b.w./h} \mathrm{s.c.)} \mathrm{the} \mathrm{decrease} \mathrm{in} \mathrm{heart} \mathrm{rate}$ and blood pressure due to d,l-propranolol was nearly abolished. The heart rate showed only a small decrease after 30 and 45 min (fig. 5). Substitution with $0.3 \mathrm{mg} / \mathrm{kg}$ b.w./h s.c. corticosterone did not prevent the hypotensive action and bradycardia (fig. 5).

Central injection of $d, 1$-propranolol into a lateral brain ventricle of adrenalectomized rats $(0.5$ and $1.5 \mathrm{mg} / \mathrm{kg})$ caused cardiovascular changes which were less pronounced than those following the peripheral injection of comparable doses (table 2). Significant changes in blood pressure and heart rate were only observed with the highest dose of d,l-propranolol. The maximal responses occurred after the same time interval as after peripheral injection of d,l-propranolol.

Parasympathetic activation did not seem to be an important factor in causing the bradycardia or hypotension since bilateral vagotomy and pretreatment with atropine $(5 \mathrm{mg} /$ $\mathrm{kg}$ ) did not prevent the cardiovascular effects of d,l-propranolol in adrenalectomized SHR. Maximal decreases in blood pressure and heart 


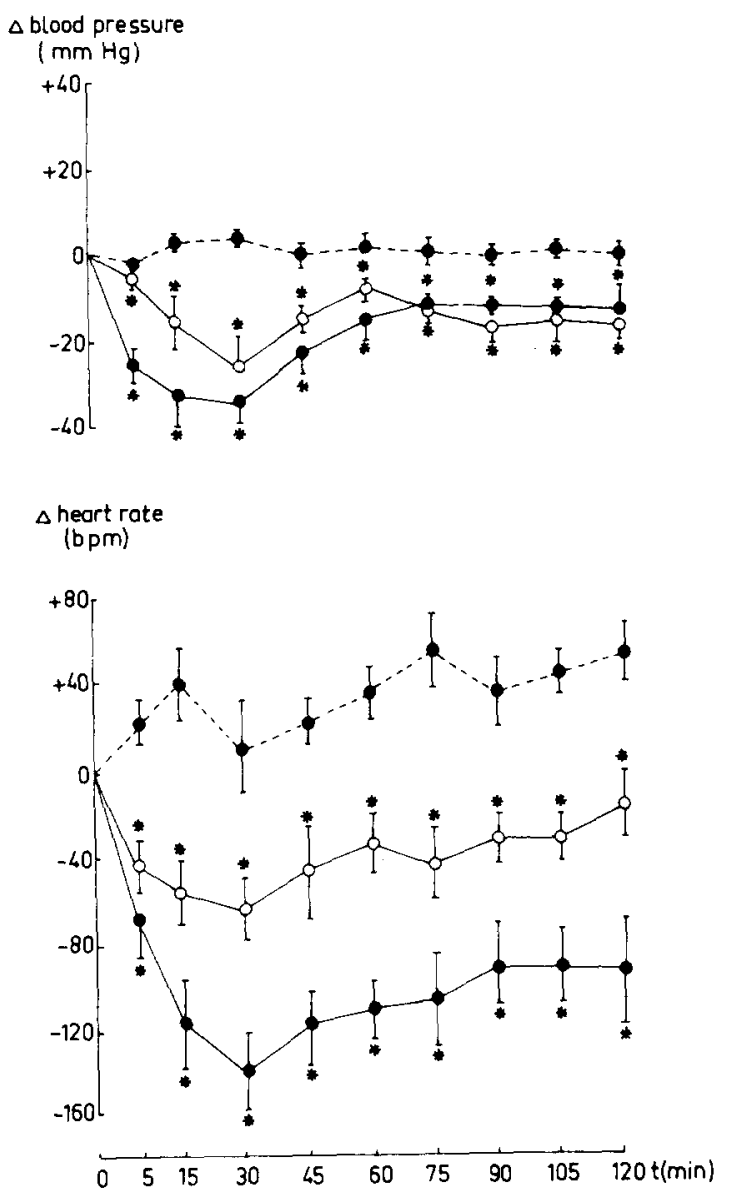

Fig. 1. Effect of various doses of d,l-propranolol on mean blood pressure and heart rate of adrenalectomized conscious spontaneously hypertensive rats. -.... saline (basal values: $128 \pm 5 \mathrm{~mm} \mathrm{Hg}$ and $348 \pm 13 \mathrm{bpm}, \mathrm{n}=8$ ). $\longrightarrow$ olol (basal values: $128 \pm 5 \mathrm{~mm} \mathrm{Hg}$ and $349 \pm 14 \mathrm{bpm}$, $\mathrm{n}=6$ ). $\longrightarrow 5 \mathrm{mg} / \mathrm{kg}$ s.c. propranolol (basal values: $134 \pm 5 \mathrm{~mm} \mathrm{Hg}$ and $396 \pm 20 \mathrm{bpm}, \mathrm{n}=7$ ). $* \mathbf{P}<0.05$.

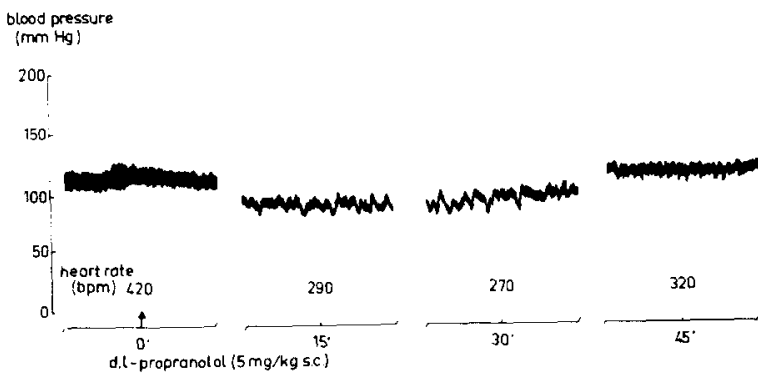

Fig. 2. Blood pressure recording depicting the response to d,l-propranolol $(5 \mathrm{mg} / \mathrm{kg} \mathrm{s.c.)}$ in an adrenalectomized conscious spontaneously hypertensive rat.

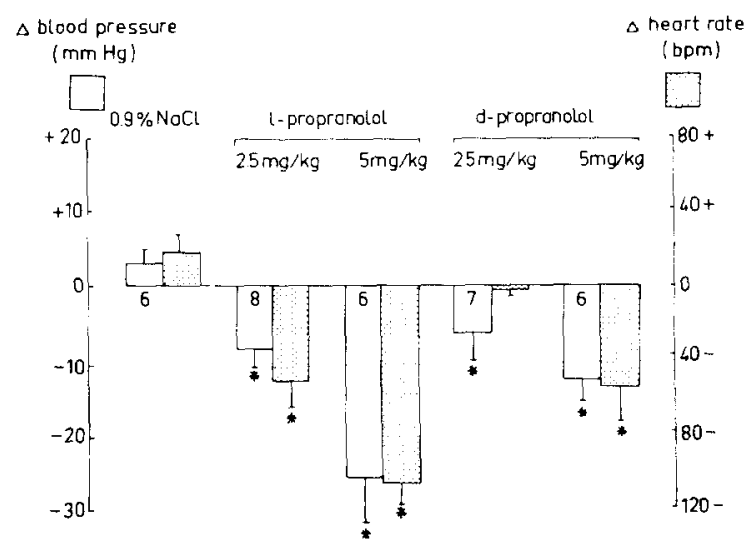

Fig. 3. Maximal decreases in mean blood pressure and heart rate, $15-30 \mathrm{~min}$ after administration of different doses of $d$ - and 1-propranolol to adrenalectomized conscious spontaneously hypertensive rats. Basal values did not differ significantly from those depicted in fig. $1 . * \mathrm{P}<0.05$.
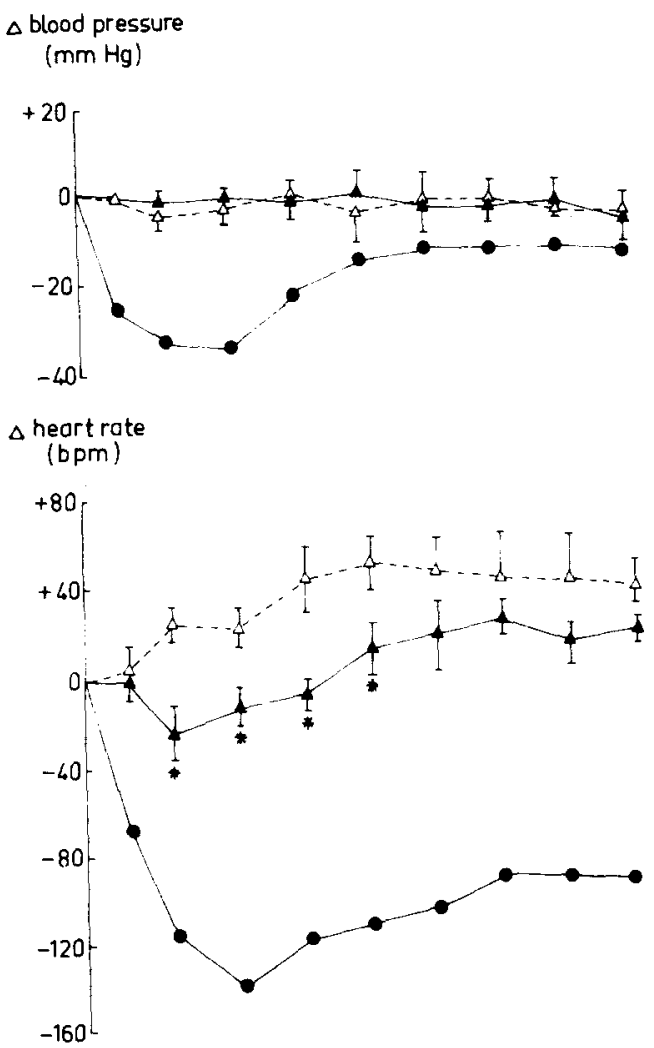

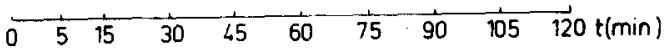

Fig. 4. Effect of d,1-propranolol ( $5 \mathrm{mg} / \mathrm{kg}$ s.c.) on mean blood pressure and heart rate of adrenal demedullated conscious spontaneously hypertensive rats. $\triangle$ A propranolol after demedullation (basal values: $128 \pm 7 \mathrm{~mm} \mathrm{Hg}$ and $313 \pm 11 \mathrm{bpm}, \mathrm{n}=6$ ). $\triangle \ldots . \triangle$ saline after demedullation (basal values: $145 \pm 3 \mathrm{~mm} \mathrm{Hg}$ and $328 \pm 6 \mathrm{bpm}, \mathrm{n}=5$ ). The group of adrenalectomized rats treated with propranolol alone $(\longrightarrow)$ is taken from fig. $1 . * P<0.05$. 
TABLE 2

Effect of central (i.c.v.) administration of various doses of d,l-propranolol on mean blood pressure and heart rate of adrenalectomized conscious spontaneously hypertensive rats.

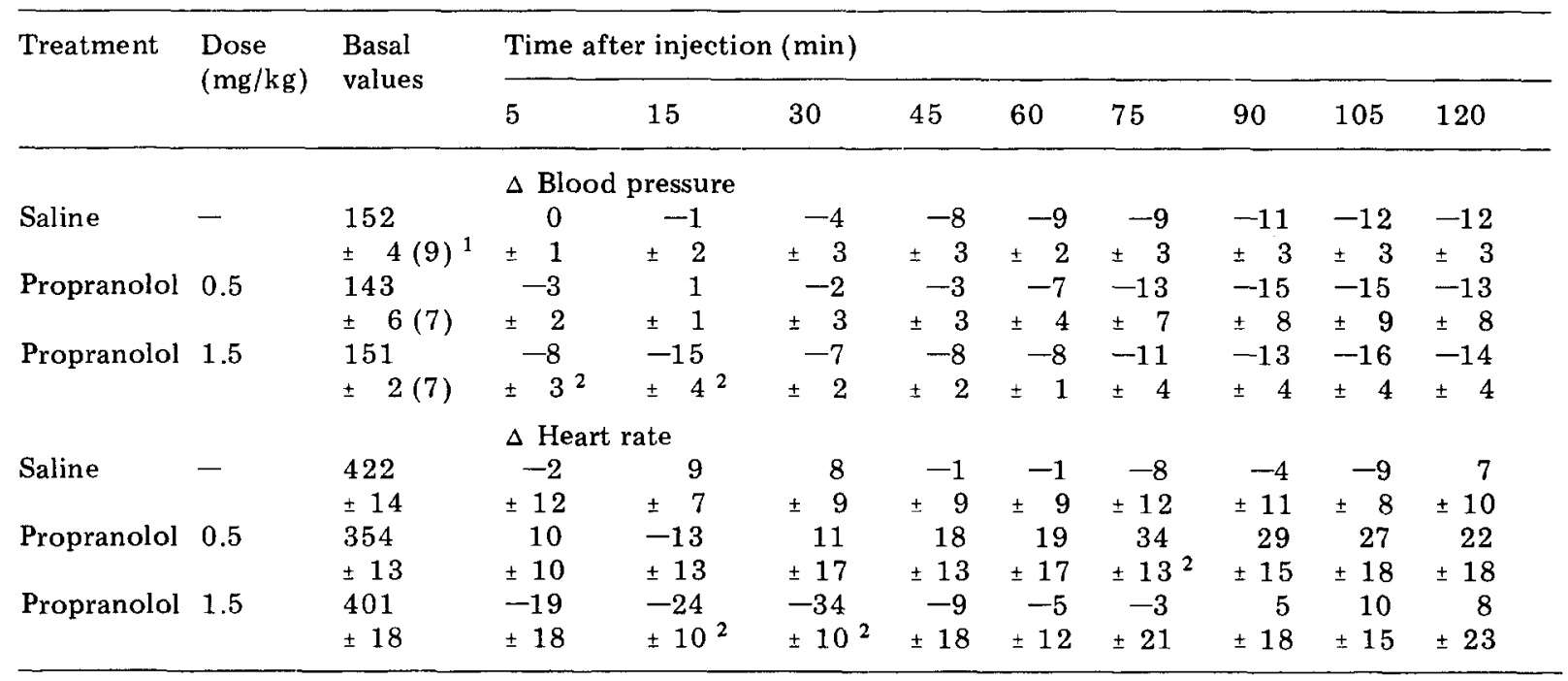

1 Number of animals is given in parentheses.

${ }^{2} \mathrm{P}<0.05$, compared to corresponding control value (saline treatment).

\section{TABLE 3}

Effect of d,l-propranolol ( $5 \mathrm{mg} / \mathrm{kg} \mathrm{s.c.)}$ on mean blood pressure and heart rate of adrenalectomized conscious normotensive and hypertensive rats.

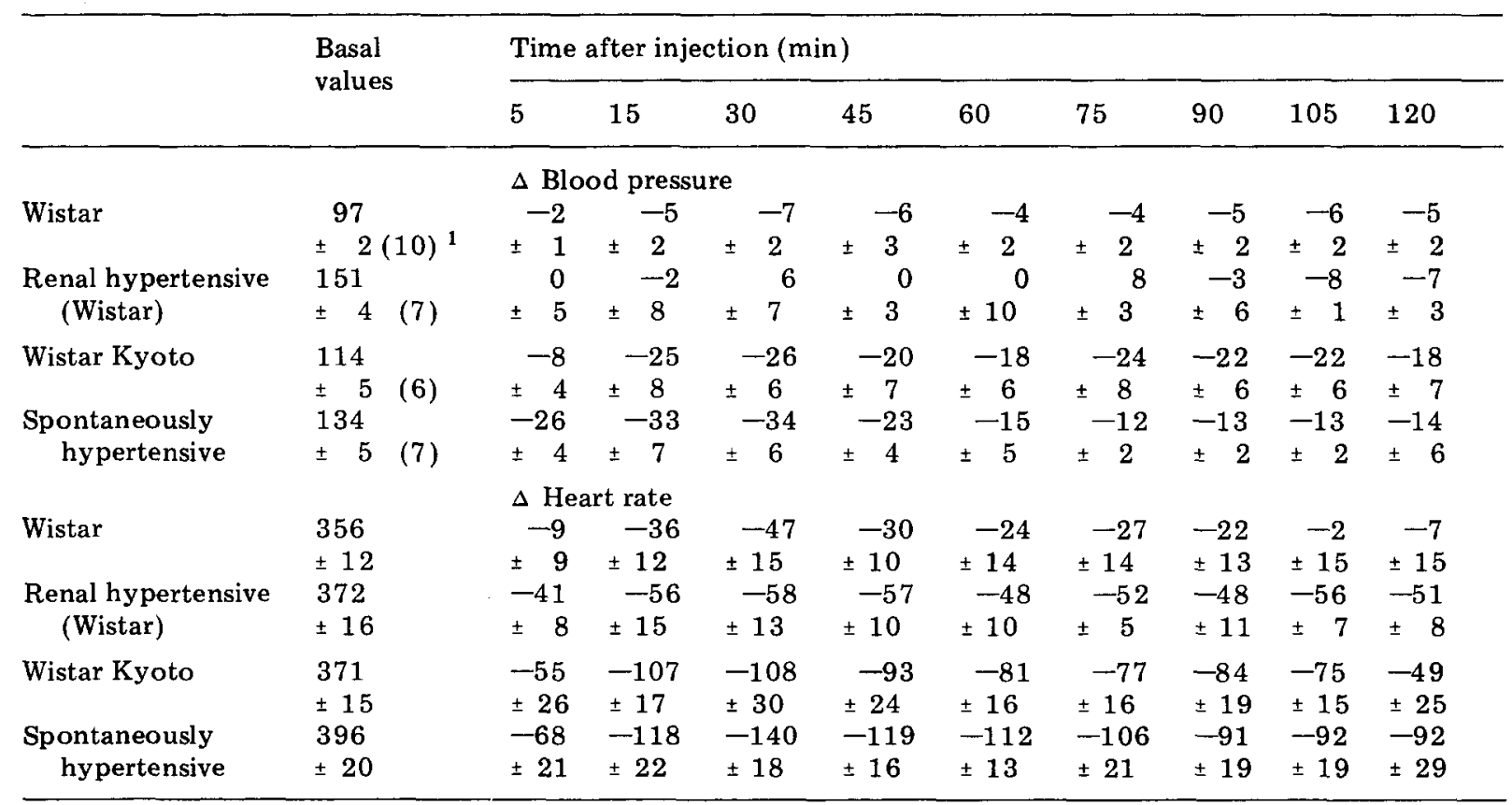

1 Number of animals is given in parentheses. 

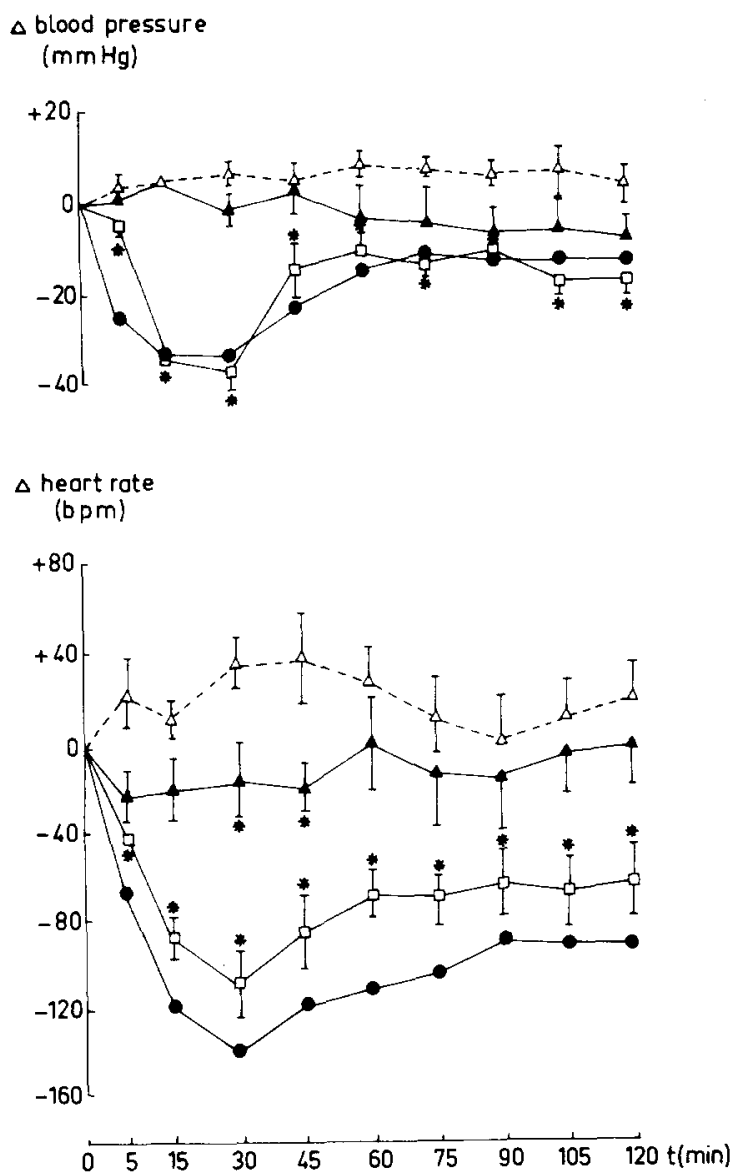

Fig. 5. Effect of d,l-propranolol ( $5 \mathrm{mg} / \mathrm{kg}$ s.c.) on mean blood pressure and heart rate of adrenalectomized conscious spontaneously hypertensive rats receiving corticosterone as replacement therapy. $\square$ propranolol $+30 \mu \mathrm{g} / 100 \mathrm{~g} \mathrm{b.w./h}$ corticosterone (basal values: $128 \pm 4 \mathrm{~mm} \mathrm{Hg}$ and $387 \pm$ $2 \mathrm{bpm}, \mathrm{n}=10), \quad \longrightarrow$ propranolol $+100 \mu \mathrm{g} /$ $100 \mathrm{~g} \mathrm{b.w.} / \mathrm{h}$ corticosterone basal values: $129 \pm 3$ $\mathrm{mm} \mathrm{Hg}$ and $357 \pm 20 \mathrm{bpm}, \mathrm{n}=5$ ). $\triangle \ldots . \Delta$ saline + $100 \mu \mathrm{g} / 100 \mathrm{~g} \mathrm{b.w./h}$ corticosterone (basal values: $121 \pm 11 \mathrm{~mm} \mathrm{Hg}$ and $342 \pm 20 \mathrm{bpm}, \mathrm{n}=5$ ). The group of rats treated with propranolol alone $(\bullet)$ is taken from fig. $1 . * \mathrm{P}<0.05$.

rate were $-40 \pm 5 \mathrm{~mm} \mathrm{Hg}$ and $-140 \pm 3 \mathrm{bpm}$ respectively ( $\mathrm{n}=4, \mathrm{P}<0.05$ for both parameters).

In order to study the role of the kidneys and of renin, d,l-propranolol $(5 \mathrm{mg} / \mathrm{kg})$ was administered to adrenalectomized rats which

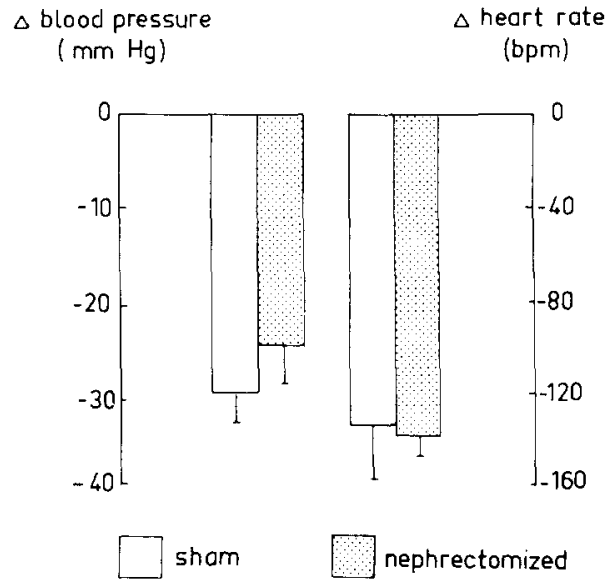

Fig. 6. Effect of d.l-propranolol ( $5 \mathrm{mg} / \mathrm{kg}$ s.c.) on mean blood pressure and heart rate of nephrectomizedadrenalectomized conscious spontaneously hypertensive rats. Basal values for the nephrectomized group were $121 \pm 5 \mathrm{~mm} \mathrm{Hg}$ and $409 \pm 9 \mathrm{bpm}(\mathrm{n}=7)$ and for the control group $130 \pm 5 \mathrm{~mm} \mathrm{Hg}$ and $340 \pm$ $20 \mathrm{bpm}(\mathrm{n}=6)$.

had also been nephrectomized. There was no significant inhibition of the hypotensive action or of the bradycardia (fig. 6).

The inhibitory effects of d,l-propranolol were not restricted to the SHR, since similar effects were observed in the adrenalectomized normotensive Wistar Kyoto rat (table 3). The responses were different in the Wistar strain. d,l-Propranolol did not lower the blood pressure significantly during the $2 \mathrm{~h}$ observation period in either the adrenalectomized normotensive Wistar rat or the adrenalectomized renal hypertensive Wistar rat. The heart rate decreased but the response was less than half that of the Wistar Kyoto and SHR.

\section{Discussion}

The present experiments aimed to study the role of the adrenals in the effects of propranolol on blood pressure and heart rate of the SHR. Although no substantial blood pressure lowering effect of propranolol occurred in the intact conscious SHR, 
we observed a profound acute hypotension and bradycardia after adrenalectomy. The failure of propranolol to decrease blood pressure in rats with established hypertension has been previously noted (Lundgren, 1974; Fernandes et al., 1977; Pak et al., 1977). Several reports indicate that propranolol can even induce a pressor response which might be due to the release of catecholamines from the adrenal medulla (Yamamoto and Sekiya, 1972; Brunner and Hedwall, 1970; Grewal and Kaul, 1970; Regoli, 1970). Such a release of catecholamines may have contributed to the failure to decrease blood pressure by $\beta$-blockers. In our experiments however the acute decrease in blood pressure after propranolol in the adrenalectomized SHR did not depend on the absence of the adrenal medulla, since no substantial decreases in blood pressure or heart rate occurred in demedullated animals. In contrast the adrenal cortex seems to be important, since replacement therapy of adrenalectomized SHR with doses of corticosterone resulting in a near control level of corticosterone $(25 \mu \mathrm{g} / 100 \mathrm{ml}$ plasma; unpublished observation) prevented the hypotension and bradycardia after propranolol. Adrenal corticosteroids therefore seem to be responsible for the absence of inhibitory effects of propranolol on the cardiovascular system of SHR.

It is not clear in which way corticosterone interferes with the hypotension and bradycardia due to propranolol. There have been reports relating to the action of glucocorticoids in inhibiting the extraneuronal as well as the neuronal uptake of catecholamines (Iversen and Salt, 1970; Nicol and Rae, 1972; Bassett and Cairncross, 1976). $\beta$-Blockers have been shown to reduce noradrenaline release during adrenergic nerve stimulation in studies carried out both in vivo (Dahlöf et al., 1975; Yamaguchi et al., 1977) and in vitro (Adler-Graschinsky and Langer 1975; Dahlöf et al., 1978). These effects seem to be mediated by a presynaptic $\beta$-adrenoceptor mediating a positive feed-back regulation of noradrenaline release from sympathetic nerve terminals (see Langer, 1977). An effect of $\beta$-blockers on presynaptic mechanisms has been suggested to account for the hypotensive action of propranolol (see De Champlain, 1978). It is possible that in the presence of the corticosteroids the inhibition of the uptake mechanisms might therefore potentiate the effect of endogenous neurotransmitters compensating for the diminished release and thereby antagonizing the cardiovascular effect of propranolol.

Several investigators point to an involvement of the central nervous system (Day and Roach, 1974; Reid et al., 1974; Myers et al., 1975; Garvey and Ram, 1975). In our experiments, however, the central injection of propranolol induced a hypotension which was less profound than that following the peripheral administration of comparable doses. A central site of action therefore does not seem likely. However since propranolol diffuses quickly across the blood-brain barrier, a central site of action cannot be excluded.

Which cardiovascular parameters do mediate the anti-hypertensive action of propranolol under our conditions remains to be elucidated. Suppression of renin release by propranolol is suggested to account for the anti-hypertensive effect in patients with high plasma renin activity (Bühler et al., 1972). In our experiments however, renal renin did not play a major role since in adrenalectomizednephrectomized SHR there was no significant inhibition of the blood pressure lowering effect of propranolol. A lowering in cardiac output (Prichard and Gillam, 1969; Tarazi and Dustan, 1972) is not unlikely. However, under the experimental conditions used no correlation could be established between the negative chronotropic and the anti-hypertensive effect of propranolol. Whether peripheral vasodilatation contributed to the anti-hypertensive effect of propranolol remains a matter of speculation until cardiac output is measured and total peripheral resistance is calculated in the adrenalectomized SHR.

In addition to its $\beta$-adrenergic blocking capacity, d,l-propranolol possesses local anes- 
thetic activity (Morales-Aguilera and Vaughan Williams, 1965). This unspecific effect might have contributed to the strong bradycardia in addition to the $\beta$-adrenergic blocking activity. The $\beta$-antagonistic property of $\alpha, 1$-propranolol, however, is due mainly to the l-isomer, while the d-isomer of propranolol has only weak $\beta$-antagonist activity, and both exhibit equivalent local anesthetic activity (Howe and Shanks, 1966; Barrett and Cullum, 1968).

The present results with adrenalectomized SHR suggest that the cardiovascular effects of d,l-propranolol are mainly ascribable to the $\beta$-adrenergic capacity of the drug. However, because a higher dose of l-propranolol was necessary to induce a fall in blood pressure comparable to that expected from the dose of d,l-propranolol used, we cannot exclude an additional effect of d-propranolol.

The cardiovascular effects of propranolol were only observed to a statistically significant extent in the Wistar Kyoto strain. Genetically determined differences may explain the observed differences. Despite the difference in blood pressure levels, the normotensive Wistar Kyoto strain and the SHR have many characteristics in common, e.g., comparable levels of salivary gland reninlike enzyme which are higher than those of several other rat strains (De Jong et al., 1972), as well as comparable levels of brainstem dopa decarboxylase activity which were reported to be lower than that of the Wistar strain (Yamabe et al., 1973).

\section{Acknowledgement}

This research was supported by a grant from the Organization for Health Research TNO, the Netherlands.

\section{References}

Adler-Graschinsky, E. and S.Z. Langer, 1975, Possible role of a $\beta$-adrenoceptor in the regulation of noradrenaline release by nerve stimulation through a positive feedback mechanism, Brit. J. Pharmacol. 53,43 .
Barrett, A.M. and V.A. Cullum, 1968, The biological properties of the optical isomers of propranolol and their effects on cardiac arrhythmias, Brit. $\mathrm{J}$. Pharmacol. 34, 43.

Bassett, J.R. and K.D. Cairncross, 1976, Effect of stress on the uptake of ${ }^{3} \mathrm{H}$-norepinephrine into rat myocardium, Pharmacol. Biochem. Behav. 4,39 .

Brunner, H.O. and P.R. Hedwall, 1970, Role of adrenal catecholamines in reflex cardiovascular adjustment in the renal hypertensive rat, NaunynSchmiedeb. Arch. Pharmacol. 265, 387.

Buckingham, R.E., T.C. Hamilton and D. Robson, 1978, Diminishing hypotensive effect of increasing doses of pindolol in doca/saline hypertensive rats, Brit. J. Pharmacol. 62, 362.

Bühler, F.T., J.H. Laragh, L. Baer, E.D. Vaughan and H.R. Brunner, 1972, Propranolol inhibition of renin secretion; a specific approach to diagnosis and treatment of renin dependent hypertensive diseases, New Engl. J. Med. 287, 1209.

Bühler, F.R., J.H. Laragh, E.D. Vaughan Jr., H.R. Brunner, H. Gravas and L. Baer, 1973, Antihypertensive action of propranolol: specific antirenin response in high and normal renin forms of essential, renal, renovascular and malignant hypertension, Amer. J. Cardiol. 32, 511.

Dahlöf, C., B. Ljung and B. Åblad, 1978, Increased noradrenaline release in rat portal vein during sympathetic nerve stimulation due to activation of presynaptic $\beta$-adrenoceptors by noradrenaline and adrenaline, European J. Pharmacol. 50, 75.

Day, M.D. and A.G. Roach, 1974, Cardiovascular effect of $\beta$-adrenoceptor blocking agents after intracerebroventricular administration in conscious normotensive cats, Clin. Exptl. Pharmacol. Physiol. $1,333$.

De Champlain, J., 1978, The contribution of the sympathetic nervous system to arterial hypertension, Can. J. Physiol. Pharmacol. 56, 341.

De Jong, W., W. Lovenberg and A. Sjoerdsma, 1972, Renin-like activity in submaxillary gland in several strains of rats including the spontaneously hypertensive rat, Biochem. Pharmacol. 21, 2123.

Farmer, J.B. and G.P. Levy, 1968, A comparison of some cardiovascular properties of propranolol, MJ 1999 and quinidine in relation to their effects in hypertensive animals, Brit. J. Pharmacol. 34, 116.

Fernandes, M., G. Onesti, A. Weder, R. Dykyj, A.B. Gould, K.E. Kim and C. Swartz, 1976, Experimental mode of severe renal hypertension, $J$. Lab. Clin. Med. 87, 897.

Fernandes, M., G. Onesti, R. Fiorentini, A.B. Gould, K.E. Kim and C. Swartz, 1977, Effect of propranolol on blood pressure and renin in renal hypertension in the rat, Clin. Sci. Mol. Med. 52, 107. 
Forman, B.H. and P.J. Mulrow, 1974, Effect of propranolol on blood pressure and plasma renin activity in the spontaneously hypertensive rat, Circulation Res. 35, 215.

Frohlich, E.D., R.C. Tarazi, H.P. Dustan and I.H. Page, 1968, The paradox of $\beta$-adrenergic blockade in hypertension, Circulation $37,417$.

Garvey, H.L. and N. Ram, 1975, Centrally induced hypotensive effects of $\beta$-adrenergic blocking drugs, European J. Pharmacol. 33, 283.

Grewal, R.S. and C.I. Kaul, 1970, Mechanism of the antagonism of the hypotensive action of guanethidine by propranolol, Brit. J. Pharmacol. 38, 771.

Hayden, J.F., L.R. Johnson and R.P. Maickel, 1966, Construction and implantation of a permanent cannula for making injections into the lateral ventricle of the rat brain, Life Sci. 5, 1509.

Howe, R. and R.G. Shanks, 1966, Optical isomers of propranolol, Nature (London) 210, 1336.

Iversen, L.L. and P.J. Salt, 1970, Inhibition of catecholamine Uptake Un $_{2}$ by steroids in the isolated rat heart, Brit. J. Pharmacol. 40, 528.

Langer, S.Z., 1977, Presynaptic receptors and their role in the regulation of transmitter release, Sixth Gaddum Memorial Lecture, Brit. J. Pharmacol. 60,481 .

Leenen, F.H.H. and E.W. Ackerman, 1976, Effects of propranolol on development and maintenance of severe renal hypertension in rats, Clin. Exptl. Pharmacol. Physiol, 3, 575.

Leenen, F.H.H. and W. de Jong, 1971, A solid silver clip for induction of predictable levels of renal hypertension in the rat, J. Appl. Physiol. 31, 142.

Lundgren, Y., 1974, Blood pressure and vascular design in renal hypertension in rats after prolonged propranolol treatment, Acta Physiol. Scand. 91, 409.

Menard, J., J.M. Alexandre, J.F. Guidicelli, C. Auzan and C. Chevillard, 1973, Lack of antihypertensive effects of chronic administration of d,l-propranolol in Grollman rats, Arch. Intern. Pharmacodyn. Therap. 202, 298.

Morales-Aguilera, A. and E.M. Vaughan-Williams, 1965, The effect on cardiac muscle of receptor antagonists in relation to their activity as local anesthetics, Brit. J. Pharmacol. 24, 332.

Myers, M., G.P.J. Lewis, J.L. Reid and C.T. Dollery, 1975, Central noradrenergic mechanisms and the cardiovascular effects of intra-cerebroventricular $(+)$ - and (-)-propranolol in the conscious rabbit, Neuropharmacology 14, 221.

Nicol, C.J.M. and R.M. Rae, 1972, Inhibition of accumulation of adrenaline and noradrenaline in arterial smooth muscle by steroids, Brit. J. Pharmacol. 44,361 .

Pak, C.H., M.D. Matsunaga, J. Yamamoto, J. Kira, K. Ogino and C. Kawai, 1977, Effect of propranolol on blood pressure and plasma renin concentration in renovascular hypertensive rats, Jap. Heart J. 18, 392.

Prichard, B.N.C. and P.M.S. Gillam, 1969, Treatment of hypertension with propranolol, Brit. Med. J. 1,7 .

Ram, N., U.C. Hesse and R.D. Heilman, 1977, The effects of propranolol $\mathrm{HCl}$ in hippocampal-lesioned rats, Arch. Intern. Pharmacodyn. Therap. 229, 138.

Regoli, D., 1970, Pressor action of beta blocking agents in rats, Can. J. Physiol. Pharmacol. 48, 481.

Reid, J.L., P.J. Lewis, M.G. Myers and C.T. Dollery, 1974, Cardiovascular effects of intracerebroventricular d-, l-, and d,l-propranolol in the conscious rabbit, J. Pharmacol. Exptl. Therap. 188, 394.

Roba, J., G. Lambelin and A.F. De Schaepdryver, 1972 , Antihypertensive activity of four $\beta$-blocking agents in spontaneously hypertensive rats, Arch. Intern. Pharmacodyn. Therap. 200, 182.

Sweet, C.S., A. Scriabine, H.C. Wenger, C.T. Ludden and C.A. Stone, 1977, Comparative antihypertensive effects of intracerebroventricular injection vs. oral administration of $\beta$-adrenergic blocking drugs in the spontaneously hypertensive rat, in: Regulation of Blood Pressure by the Central Nervous System, eds. G. Onesti, M. Fernandes and K. Kim (Grune and Stratton, New York).

Tarazi, R.C. and H.P. Dustan, 1972, $\beta$-Adrenergic blockade in hypertension; practical and theoretical implication of long-term hemodynamic variations, Amer. J. Cardiol. 29, 633.

Vavra, I., H. Tom and E. Greselin, 1973, Chronic propranolol treatment in young spontaneously hypertensive and normotensive rats, Can. J. Physiol. Pharmacol. 51, 727.

Weiss, L., Y. Lundgren and B. Folkow, 1974, Effects of prolonged treatment with adrenergic $\beta$-receptor antagonists on blood pressure, cardiovascular design and reactivity in spontaneously hypertensive rats (SHR), Acta Physiol. Scand. 91, 447.

Yamabe, H., W. de Jong and W. Lovenberg, 1973, Further studies on catecholamine synthesis in the spontaneously hypertensive rat: catecholamine synthesis in the central nervous system, European J. Pharmacol. 22, 91.

Yamaguchi, N., J. DeChamplain and F.A. Nadeau, 1977, Regulation of norepinephrine release from cardiac sympathetic fibers in the dog by presynaptic $\alpha$ - and $\beta$-receptors, Circulation Res. 41 , 108.

Yamamoto, J. and A. Sekiya, 1972, Further studies on the pressor action of propranolol in the rat, Arch. Intern. Pharmacodyn. Therap. 198, 347.

Zacharias, F.J., K.J. Cohen, J. Prestt, J. Vickers and B.G. Wall, 1972, Propranolol in hypertension: a study of long-term therapy, 1964-70, Amer. Heart J. 83, 755. 